\title{
Business Ecosystems as the Approach to Create Value and Appropriate Value for Small Firms in Emerging Markets
}

\author{
Nicholaus Bhikolimana Tutuba \\ Mzumbe University \\ Hawa Petro Tundui \\ Mzumbe University \\ Jasinta Samwel Msamula \\ Mzumbe University
}

How can firms with limited scope and scale compete to create value and appropriate value beyond their existing business? Firms in the beekeeping industry in Tanzania, beekeepers, in particular, have failed to create sufficient value and appropriate a sizable value as they have limited financial resources to invest. The business ecosystem approach indicates that firms can jointly create value that can capture sizable value through the ecosystem's resources. In the beekeeping industry, the ecosystem should be structured around the honey collection center and its efficiency depends on productivity, lock-in, channel management, complementarity, and the position and activities of actors. Firms' ability to successfully create value and capture value depends on the ability to team up with partners with complementary assets and skills in an industry architecture. Value creation and value appropriation cannot materialize if partners are not committed and willing to work together on long term bases.

Keywords: Beekeeping, Business Ecosystem, Business Model, Industrial Architecture

\section{INTRODUCTION}

Successful businesses are those that can create value for their customers and capture sufficient value for all participating firms while improving the wellbeing of society. Management scholars have been concerned with value creation through innovation: "Greater value creation [...] depends on the firms' ability to innovate successfully" (Adner \& Kapoor 2010, p.306). But creating value only is not enough because some firms failed to commercialize their innovations. The challenge is not just creating value, but capturing that value as well based on a sustainable competitive advantage (Pisano \& Teece, 2007). Insufficient value capture hurts not only enterprises but society as well (Leten et.al., 2013). To have prosperous rural economies/industries it is necessary business actors earn sufficient profits to warrant further investments.

In Tanzania, the beekeeping industry has the uppermost potential for production (Mwakatobe \& Mlingwa, 2006; Guyo, 2015) and commercialization (Tutuba et.al., 2019) of bee products. But, this 
potential has not fully utilized: productivity is still low and honey markets are still under-served. The beekeeping industry is poorly organized and commercialization practices are still weak, and disorganized (International Trade Centre [ITC], 2015). Limited by financial resources and technical capabilities, beekeepers remained local and poor: They failed to capture a sizable value despite that they are the primary producers of honey (Tutuba \& Vanhaverbeke, 2018). But creating value and capturing value for all participating firms and the society cannot be done in a vacuum and by a single firm, it requires a properly developed and managed business network or ecosystem (Moore, 1993; Adner \& Kapoor, 2010). Firms with "complementary skills and assets" (Vanhaverbeke, 2017, p.81) should be coordinated and structured to efficiently create value and cordially share the created value. They re-construct their business relations by sharing the same market opportunity and avoiding direct competition (Chesbrough, et.al., 2006; Collins, et.al., 2015). When firms do not have scale and scope to compete effectively and capture enough value "have no other choice than changing their business structure" (Vanhaverbeke, 2017, p.16). In this regard, beekeepers cannot capture enough value from the beekeeping industry if they keep working in the same way they are working. Similarly, the beekeeping industry cannot capture enough value for all industry actors and society if it keeps operating in the same industry architecture (Jacobides et.al., 2006). Teaming up of firms with complementary skills and assets is unavoidable. Therefore, based on the industry architecture (Jacobides et al, 2006) and business ecosystem (Adner, 2017; Jacobides et al, 2018) literature, we focus on changing the beekeeping industry architecture through the ecosystem approach: How an industry architecture can be changed to benefit beekeepers in the beekeeping ecosystem in Tanzania? We look first at how beekeeping firms can jointly create value with their ecosystem partners, and secondly, how beekeepers can capture greater value through the ecosystem's resources.

The study is structured as follows. Following this introduction, we outline the industry architecture, business ecosystem, and business model concepts. Thereafter, we present the methodology and approach, followed by study findings. Then we offer our interpretation of the findings. Lastly, we summarize the main findings, the limitations of our study and explore different directions for future research.

\section{The Industry Architecture}

Complementary to the strategy and business management research on value creation and value capture, Jacobides (2006) introduced a new concept of 'industry architecture'. The industry architecture (IA) concept is proposed to describe how labor is organized, and how profit is appropriated among industry actors within an industry (Jacobides et.al., 2006; Jacobides \& Kudina, 2013; Jacobides, 2016). The IA provides two models: a model showing value creation and the division of labor, and a model showing value capture and the division of revenue (Tee \& Gawer, 2009). It focuses on who is benefiting from innovation through how the profit along the value chain gets divided among industry participants. However, observation of today's complex business environment shows that different (types of) actors compete to capture more value by fighting each other within the value system. They try to make their slice of the pie bigger by making someone else's slice smaller (Vanhaverbeke \& Cloodt, 2006; Collins et.al., 2015). For example, in a beekeeping industry, honey traders try to increase their slice (or value pie) by making the slice of the beekeepers smaller. This has caused the beekeeping value chain behavior to become opportunistic: Customers (traders) switch suppliers (beekeepers) if they can negotiate better deals. Similarly, suppliers let down customers if they get a better offer from someone else: honey sideselling behavior (Tutuba et.al., 2019). Likewise, beekeepers are not properly coordinated both among themselves and with other actors in the value-creating system. Accordingly, the beekeeping IA has fragmented and commercially weak actors who have neither trust nor commitment among themselves. Their business relationship is arm's-length, and value appropriation depends on the bargaining power of the individual firm. This value appropriation model increases the fights for value capture among actors in the industry: Beekeepers who have relatively low bargaining power capture less value.

As Jacobides (2006) argue that the IA defines the strategic constructs through which firms can work together as an ecosystem (Jacobides et.al., 2018) to create value for customers and capture value for participating firms in the particular industry. The IA concept considers how architecture shapes 
capabilities (Teece, 2016), and how different types of capabilities fit together to define the structure of firms and industries alike. Firms collaborate to receive complimentary products and components in a value network (Amit \& Zott, 2001) or an ecosystem (Iansiti \& Levien, 2004) i.e., the combination of the value chain and complementary products (Yaghmaie \& Vanhaverbeke, 2019). Therefore, the beekeeping IA should be changed from transactional to a collaborative model. Firms in the beekeeping industry should be aligned, coordinated, and organized to share the roles, activities, and capabilities i.e., changing the IA through the ecosystem approach.

\section{The Business Ecosystem}

When Moore (1993), introduced the term 'ecosystem' in the field of business strategy he emphasized that firms should not be viewed as members of a single industry but as members of a business "ecological unit" comprising of businesses from different industries with coevolving capabilities to deliver value to customers. The term ecosystem refers to a set of interacting firms that depend on each other's activities and resources; and a business ecosystem as a group of symbiotic businesses collectively providing value propositions (Amit and Zott, 2001; Osterwalder \& Pigneur, 2010) to customers. The business ecosystem fruition relies on the technological and business leadership of firms - also referred to as an industry leader (Moore, 1993), a keystone firm (Iansiti \& Levien, 2004), orchestrator (Vanhaverbeke \& Cloodt, 2006), an ecosystem captain (Teece, 2016), a platform leader (Gawer \& Cusumano, 2014), or a focal actor (Kapoor, 2018 ) - that provide common standards and hence a [stage] platform around which other actors align their investments and strategies to provide inputs and complementary products. In this regard, a business ecosystem comprises a community of stakeholders, participating [primary] actors, competitors, and customers. The key to a business ecosystem is the "orchestrator", who have a strong influence over the co-evolutionary processes. The orchestrator influences other firms within the industry and also the firms influence each other in the evolution process. For example in the beekeeping industry, honey traders can influence beekeepers and customers towards delivering honey to the market. And beekeepers can influence each other to improve productivity and aggregation of honey. Most important for firms in business ecosystems are the capabilities to co-evolve around innovation sustainably.

Furthermore, different ecosystem analogies (Adner, 2017; Jacobides et.al., 2018; Tsujimoto et.al., 2018) and formulations (Moore, 1993; Gawer \& Cusumano, 2008; 2014; Adner \& Kapoor, 2010; Leten et.al. 2013; Kapoor, 2018) exists depending on the unit of analysis and scope of the study. Nevertheless, while the ecosystem perspectives are conceptually distinct, they are mutually consistent, as they relate to each other. Therefore, as we focus on changing the IA of the beekeeping industry through a business ecosystem we bound to business ecosystems aspect, the ecosystem-as-structure approach as a unit of analysis. "Ecosystem-as-structure offers a complementary approach to considering interdependent value creation [...] starts with a value proposition and seeks to identify the set of actors that need to interact for the proposition to come about" (Adner, 2017, p.41). We proceed in this way because the approach offers a more actionable perspective on interdependence (Jacobides et.al., 2018). It focuses on configurations of activities i.e., who does what? and sharing of profits, i.e., who gets what? (Tee \& Gawer, 2009) defined by a value proposition as well as value appropriation; the architecture of the business model (Amit \& Zott, 2016; Teece, 2018b). Consequently, we conceptualize business ecosystems as the alignment structure of the set of business partners/actors with varying degrees of multilateral, non-generic complementarities that need to interact for a focal value proposition to materialize. Focusing on the components of this definition: alignment structure, multilateral, set of partners, non-generic complementarities, and materialization for a focal value proposition; and their implications (Adner, 2017; Jacobides et.al., 2018) this definition of ecosystem quite relevant for our study about the business context of the Tanzanian beekeeping industry.

Amit \& Zott (2012) propose that the ecosystem metaphor provides an interesting lens to approach the idea of value generation through cooperative efforts. In support of this idea, Adner \& Kapoor (2010) found that the success of an innovating firm often depends on activities performed by third parties in its environment, a set of actors who contribute to a central user value proposition. Kapoor (2018) proposed the explicit link between the supply-side and the demand-side of a focal offer and the consideration of the 
different types of actors from multiple industries that contribute towards a focal offer's value creation. In this regard, a business ecosystem represents an inter-linkage of different organizations by a focal actor towards the presentation of a value proposition to the focal customer. This understanding sets the theoretical foundation for the business ecosystem as a community of businesses, organizations, institutions, and individuals that impact the enterprise and the enterprise's customers and suppliers. Also, the simultaneous presence of complementarities and interdependencies between actors. "The core concern for research grounded in an ecosystem perspective is to explain firms' strategies and outcomes through the lens of such complementarities and interdependencies" (Kapoor, 2018, p.3). The representation of the structural relationship between propositions in terms of how they are connected for the value to be created and how a change in one offer may affect the contribution of other offers towards value creation (Amit \& Zott, 2012). Therefore, research grounded in an ecosystem perspective tries to explain firms' strategies and outcomes through the lens of such complementarities and interdependencies (Adner \& Kapoor, 2016; Jacobides et.al., 2018). From this theoretical understanding of the business ecosystem, it is important to understand how can [beekeeping] IA be changed to benefit [beekeepers] particular industry participants in the [beekeeping] ecosystem?

\section{Business Ecosystem: The Architecture of Value Proposition}

Based on the theoretical understanding that the business ecosystem provides a lens through which firms with different assets and capabilities team up to create value. The ecosystem's success often depends on the activities performed by interconnected firms in their environment. In the beekeeping industry, value creation is more transactional, mostly through traders, each beekeeper work solely or in small groups. This architecture bounds the value creation potential of the industry as well as beekeepers' ability to capture enough value. In this regard, we need to understand how we can change the industry architecture to create more value in the value-creating system through an ecosystem?

The business ecosystem starts with a value proposition and seeks to identify the set of actors that need to interact for the proposition to come about (Kapor, 2018). Within an ecosystem, delivering a complete customer solution [value proposition] requires the cooperation of multiple firms (Adner \& Kapoor, 2016); it entails joint entrepreneurial acts of standard-setting and market co-creation (Teece, 2016). Basically, the ecosystem orchestrator innovates, creates standards, and chooses elements of the value chain to be internalized; attract other firms into the ecosystem (Pisano \& Teece, 2007; Leten et.al., 2013), and takes responsibility for guiding the co-evolution of the system to maintain competitiveness against rival ecosystems (Gawer \& Cusumano, 2014). The success and performance of the ecosystem depend on the number of factors set and managed by the orchestrator. These elements differ concerning the industry, participating firms and degree of interdependence in the ecosystem. Nevertheless, management scholars proposed different elements - activities, actors, position, and links (Porter, 1996; Adner 2017); efficiency, novelty, complementarities, and lock-in (Amit and Zott, 2012; Hyrynsalmi et al, 2014); efficiency, enabling, convenience, and complementarities (Vanhaverbeke and Cloodt, 2006) - that characterize the blueprint for how value is (expected to be) created through interdependent collaboration of multiple actors. These elements "collectively characterize the configuration of activities and actors required for a value proposition to materialize" (Adner, 2017:43). The elements of the business ecosystem that foster value creation vary according to the type of ecosystem; and boundary settings depend on the objectives of each study. Therefore, following the definition of the business ecosystem we adapted, we argue that in the beekeeping industry in Tanzanian create value through a system where every partaking firm (actors) occupies a particular space (position) and performs some activities that add value to inputs before passing them to the next actor (links) in the chain such that value proposition is efficiently delivered to customers.

- Actors (key partnerships) are firms that take on key activities in the value-creating system; firms without which value proposition cannot be delivered, regardless of whether or not they have direct links to the orchestrator (Osterwalder \& Pigner, 2010; Adner, 2017). This element defines the network of partners that makes the business ecosystem work: "Select the right partners carefully" (Vanhaverbeke, 2017, p.126). In the beekeeping industry, the ecosystem actors include 
suppliers of raw materials e.g. carpenters (beehives), honey producers, processors, traders, transporters, and finally honey consumers.

- Activities (key activities) specify the discrete actions, a set of activities (Jacobides et.al., 2006), the most important and novel actions (Adner, 2017), that should be performed by ecosystem actors to deliver the value proposition, manage channels, maintaining customer relationships, and earn revenue (Osterwalder \& Pigner, 2010). In the beekeeping industry, key activities include honey production, aggregation, processing, and trading. Also, honey storage, transportation, and channel management. It is, however, important to note that a single actor may undertake multiple activities. Conversely, multiple actors may undertake a single activity. For example, traders can also undertake honey production and processing activities. Inversely, all actors can undertake the honey trading activity.

Also, in the beekeeping industry in Tanzania where trust among members is low, their business relationships are mostly transactional, and honey side-selling is apparent, the lock-in condition (Amit \& Zott, 2012; Hyrynsalmi et.al., 2014) is important. In 'lock-in' situations, ecosystem actors are motivated to engage in repeat transactions and are willing to continue their relationships with the firm. Beekeepers who have the side-selling behavior will be willing to continue trading and working in the ecosystem: Honey side-selling will be avoided, and business relationships among actors will be strengthened. The lock-in situation will encourage beekeepers to stay in the ecosystem and hence make it stronger, and efficient in delivering value to customers and capturing value to ecosystem actors.

- Positions specify where the activities across the system actors are located and characterize who hands off to whom (Adner, 2017). Positions describe the flow of activities or who does what? (Jacobides et al, 2006; Amit \& Zott, 2012) and defines the way an ecosystem can be structured through a business model and value chain (Zott et.al., 2011). This element is equally important in the beekeeping ecosystem as it defines the flow of activities such that every actor performs in areas of their competence and capabilities. Some actors cannot (efficiently) perform some activities because of a lack of resources or competencies. For example, beekeepers do not have resources to process honey, therefore, they are only honey producers and not processors. Consequently, beekeepers handover comb honey to processors in the value chain.

- Complementarities refer to the value-enhancing effect of the interdependencies among ecosystem activities (Tee and Gawer, 2009; Amit and Zott, 2012). Complementarity advantages emerge in scenarios where bundling multiple goods provides greater value than offering the same set of goods separately (Hyrynsalmi et al, 2014). In the beekeeping industry, complementarity is achieved by combining assets, infrastructure, and capabilities needed to support the successful production, processing, and marketing activities.

- Efficiency is defined in the context of both costs and productivity. Concerning costs, efficiency increases when the cost (broadly defined) per transaction decreases (Amit \& Zott, 2001). And in the context of productivity, efficiency can be achieved by improving productivity, reducing waste and post-harvest loss (Vanhaverbeke \& Cloodt, 2006). Furthermore, Zott et.al., (2011) identified two design themes around which the ecosystem architecture can be efficiently orchestrated: 'efficiency' and 'novelty'. In the beekeeping industry, ecosystem efficiency is necessary, and it can be achieved through both cost reduction and productivity. For example, production efficiency can be achieved by improving colony productivity, preventing absconding rates, and managing post-harvest losses. So, efficiency provides the total value creation potential of the ecosystem and the orchestrator's ability to appropriate that value.

Therefore, the presence of each of these value drivers enhances the value-creation potential of a business ecosystem in the beekeeping industry in Tanzania. Adner (2017) argues that the interdependence of value drivers can enhance the effectiveness of any single value driver. The beekeeping ecosystem should be efficiently orchestrated so that the ecosystem actors can effectively and efficiently create value, delivers value and captures value. 


\section{Business Ecosystem: The Architecture of the Value Appropriation}

In a business ecosystem, value appropriation is as important as value creation such that it helps to make the ecosystem sustainable. Value creation in an ecosystem is enabled by the presence of complementarities and interdependencies between actors (Tee \& Gawer, 2009), whose activity output contributes to the focal offer's user value proposition. Interdependencies represent a structural relationship between actors in terms of how their offers are connected for the value to be created: An actor is connected with the orchestrator if its offer influences the orchestrator's value proposition because of function-level interactions. Besides, actors can also be connected via a transaction such that an output (comb honey) of one actor (beekeeper) is an input to another actor (honey processor). While a transaction level connection is not a necessary condition for the two actors to be structurally interdependent in an ecosystem, the way the transactions are organized in an ecosystem impact the roles played by the different actors in the ecosystem.

Concerning capturing value in business ecosystems, Teece (2018a) points out that strategy becomes more complex as firms consider vibrant interactions of a multi-layered ecosystem. The competition between ecosystems tends to produce winner-take-all outcomes when there are large demand or supplyside scale economies, internal costs, and no benefit from specialization. Also, competition between ecosystems leads to an openness that results from each ecosystem trying to recruit more actors; the greater the openness, the less the opportunity for the supplier to capture value directly. "A good value capture strategy is to court well-known brands/partners who can bring large blocks of customers to the platform" (Teece, 2018a, p.1376) ..." "the selection and implementation of smart value-capturing strategies, spillovers are likely very significant" (Teece, 2018a, p.1382). Furthermore, Teece (2018a) points out several factors that increase the ability of orchestrator and ecosystem actors to capture value from downstream implementers. First, designing a business model and controlling the necessary complementary assets and technologies to internalize more of the spillovers. This is typically beyond the scope of what a single firm, beekeepers, can do, hence ecosystem architecture is important. Second, the value proposition, enabling technology, and regulatory framework should be clear at the outset such that they do not constrain value capture. Third, enabling technologies are intermediate inputs in the value chain, the orchestrator should be able to design and implement a strong business model that is capable of capturing value for all participating firms in an ecosystem: Ecosystems "makes sense only when firms can generate more profits" (Vanhaverbeke, 2017:94). And lastly, the orchestrator has a weak bargaining position when he lacks the relevant assets and capabilities to attract other actors and pose a credible threat that it will exclusively develop and commercialize the value proposition. In this regard, the business ecosystem captures value for the actors through the orchestrator's business model.

If a business ecosystem should be built around the orchestrator, then promoting collective relativity and combining activities of different firms to bring the value proposition to the market creates a problem. Adner (2017) urge that value propositions that rely on changes in ecosystem structure directly raise the question of what elements need to be (re)aligned: Who will take the role of the orchestrator, shaping the ecosystem, designing the alignment structure, and crafting the strategy to get the other actors into place? Who will accept the role of followers and agree to act per the leader's plan? What will be the key roles? Who [how] will finance the ecosystem? What rivalries need to be managed within and across ecosystems? Answering these questions, Zott \& Amit (2013) argue that the ecosystem concept could be viewed as closely related to the notion of the value [chain] system and business model because it recognizes the need to go beyond a focal firm's boundaries. Also, it adopts a more systemic perspective that emphasizes interdependencies and complementarities between actors to properly understand how value is created. "... value chains are constructs that involve multiple parties. Often, however, these relationships are treated as decomposable into bilateral relationships [...] the flow of activities along the chain follow a critical path that is well determined. While there is active bargaining on terms, there is acceptance of positions: Who is upstream (supplier) and who is downstream (buyer) is not contested" (Adner, 2017, p.52). Furthermore, Zott \& Amit (2013) argue that the business model is central to the value chain framework, in particular on the ideas that activities and multiple sources of value matter. 
Teece (2018b) describes a business model as an architecture for how a firm creates and delivers value to customers and the mechanisms employed to capture a share of that value. "The successful ecosystem is composed of multiple firms acting in concert - an ecosystem strategy can be thought of as one that takes partner firms' business model to be as critical to addressing as the focal firm's" (Adner, 2017, p.51). Therefore, we used the value chain and the business model to structure the business ecosystem in the beekeeping industry in Tanzania. We used the value chain to re-structure the beekeeping industry through which other actors will be alighted to deliver value propositions. Similarly, we used the business model canvas to structure the orchestrator's business model through which other actors in the beekeeping industry will be aligned to an appropriate value in the ecosystem.

\section{Method and Approach}

This descriptive, qualitative study was carried out in the rural areas of Tanzania, Mvomero district in particular. The area has a considerable beekeeping potential because of available diverse vegetation and ecological zones (ITC, 2015; Tutuba \& Vanhaverbeke, 2018) so it was ideal for the study. The study population contained different organizations in the beekeeping industry in Tanzania from which 18 firms - seven beekeepers, four beekeeper-processors, and seven honey traders - were purposively (Saunders et.al., 2009; Yin, 2014) selected. Using triangulated data collection techniques - unstructured face-to-face interview, observation, and group discussion - data were collected until saturation (Yin, 2014). The motivation of the study was explained to the study participants. Whenever possible, voice recording and picture taking were agreed upon with the study participants: Pictures, short clips, and note-taking were used to capture information. Furthermore, we employed the validation session to obtain valid and reliable data. Supported by the observation and prior interviews, one validation session was conducted. The purpose of the session was explained to the group. Whenever possible, the activities were recorded and photos were taken. After data collection, we transcribed the data by using transcribing software that included information with the guidance of research questions. We utilized the interpretative data analysis approach (Elliott \& Timulak, 2005) to analyze how beekeeping firms can jointly create value with their ecosystem partners and can capture sizable value through the ecosystem's resources.

\section{Study Findings}

This section presents the results of this study focusing on how to change the IA of the beekeeping industry through an ecosystem approach. We describe how firms in the beekeeping industry create value through the value chain, and capture value through the orchestrator's business model. This part of the results is meant to show how firms, beekeepers in particular, in the beekeeping industry can improve their value creation and value appropriation abilities through orchestrator's business models.

\section{The Value-creating System of the Beekeeping Ecosystem in Tanzania}

This section presents the value-creating system around which interested stakeholders, the ecosystem actors, of the beekeeping industry in Tanzania could build strategic collaboration. The proposed value chain focuses on changing the IA of the beekeeping industry through the ecosystem model. In this regard, secondary actors would also be identified to assist the primary actors, the orchestrator, in particular, to adapt to the parameters set for the respective value chain.

In the existing beekeeping IA, industry actors are working solely to deliver value to customers and capture value for themselves. The existing business relationship is transaction-based: actors [traders] with complementary assets gain more bargaining power and take the largest share of the pie while reducing the pie of [beekeepers] others. Honey traders take larger pie as they have access to markets, and resources to invest in the aggregation, refining, and packaging activities. Conversely, beekeepers remain poor because they lack resources to improve productivity, honey quality, and accessing profitable urban markets. In this regard, a different (changing this) IA is important so that the size of the pie can be increased and consequently improve the value capturing the position of the beekeepers. Then, changing the industry architecture can be achieved by aligning and cooperating with other industry actors, through the ecosystem. 
The beekeeping ecosystem begins by identifying: (1) the investor, orchestrator, or focal firm - a private firm, or cooperative - which assumes the leading role of the ecosystem; (2) potential ecosystem actors like beekeepers, honey hunters, and supermarkets to work with; (3) a potential areas of investment; and (4) specific services and service providers to work with. The operation of an ecosystem involves the commitment of participating actors and long term planning. Therefore, identifying potential actors to be involved in building the ecosystem, and signing collaboration agreements/contracts is key. Participating actors should have different assets, competencies, and capabilities so that they can abundantly contribute to the value creation activities depending on their position in the value chain.

After identifying potential ecosystem actors, defining the critical success factors of the beekeeping value-creating system is the next important stage. This sets the platform around which the roles, activities, positions, investment, and competencies are constructed upon. In the beekeeping industry, the critical success factors include production efficiency (productivity), adequate volume (quantity), reliable supply, quality assurance, hygienic practices in harvesting, storage, processing, and packaging, and traceability. Equally important may be having a known brand name as one of the entry qualifications. For an ecosystem to operate efficiently and at minimum cost, the study indicated that reliable honey supply and sizable volumes of refined honey, a minimum of five tonnes, are key issues. This can be achieved by upgrading beekeeping technology, upgrading production level, collective investment, and honey bulking or aggregation. Upgrading beekeeping technology includes the use of improved tools, equipment, knowledge, and skill in beekeeping activities. This would not only guarantee quality but also productivity and hence increasing returns to both producers (beekeepers) and processors.

Upgrading the production level can be reached by engaging a substantial number of reliable beekeepers, increasing the number of commercial beehives and bee colonies (hives occupancy rate), and improving hive productivity. We observed that, at the production level, a beekeeper could gain economic benefits by producing a minimum of $100 \mathrm{kgs}$ of honey. This amount of honey can be harvested from 10 hives, bee colonies if annual colony productivity is $10 \mathrm{kgs}$ of clear honey. In this regard, an ecosystem should have at least 500 occupied hives to get a minimum commercial quantity of refined honey: 500hives@10kgs=5,000kgs. Consequently, the ecosystem should have at least 50 devoted beekeepers who will manage 10 colonized hives at a minimum. However, at an average occupancy rate of 75 percent, an ecosystem should install at least 670 beehives: An average of 14 beehives per beekeeper. Therefore, an ecosystem can efficiently create value by installing at least 670 beehives to produce a sizable volume of honey. Furthermore, upgrading beekeeping technology, and production level allow beekeepers to improve honey quality, efficiency, and production. But this upgrading needs a sizeable investment that can well feed into an interesting value chain: Neither beekeepers nor orchestrator can do this alone. For example, at an average price of Tshs. 100,000 per beehive and 200,000 per bee suit, an ecosystem should invest about Tshs 67million in beehives (i.e., 670 beehives@100,000=67,000,000) and Tshs. 10million in bee suits (i.e., 50 bee suits@200,000=10,000,000). Therefore, the collaborative financing model is necessary to enhance access to finance for inputs and markets for honey.

Regarding honey bulking or aggregation, honey producers are organized to bring together their produces (honey) to a collection point. In the collection point, honey is received, graded (based on the agreed grading parameters), and recorded. Honey grading and record-keeping are important at this stage for both quality control and traceability. Thereafter, the collected honey can be processed or transported to the honey processing point. This model helps to achieve volume requirements, improve the quality of honey because honey of the same quality and origin will be processed together. Also, it reduces some variable costs like transportation, labor, and utilities. In this regard, the beekeeping ecosystem can achieve volume requirements and a consistent supply of quality honey if beekeepers will be organized through the collection centers. Beekeepers gain bargaining power as they work together than working solely and have a good chance to improve their pie though changing the poor conditions in the honey commercialization process.

Quality assurance is a cross-cutting success factor; it should be monitored and observed through the value-creating system - from bee forage to the point honey is consumed. Every actor whose activity has a value implication to the value proposition should observe quality factors. We observed that honey quality 
is measured in two ways: first, physical quality parameters which include water content, viscosity, color, and flavor. Secondly, a chemical quality specification which includes acidity, mineral ash, hard metals (Copper, Zinc, and Lead), and Hydroxymethyl furfural (HMF). Quality can be achieved if every activity is done in high care facilities, from which different ecosystem actors can access the services, and learn what is required to achieve the same.

Furthermore, honey blending is another important activity to create value in the beekeeping ecosystem. Honey from different beekeepers, different areas, and different vegetation, have different qualities like color, aroma, and taste. Therefore, to get homogeneous quality honey, blending is necessary. Also, honey could be blended with spices like ginger, and cinnamon to get different flavors but it also can use honey in making different confectionary products. The ecosystem then creates value by pulling together honey from different beekeepers to do the blending to have a homogenous honey product.

To ensure long-term business relationships, lock-in and collaboration strategies are necessary. All participating actors should show an interest in buying and selling honey, including comb honey, and in developing long term business relationships.

\section{The Business Model Structure of the Orchestrator in the Beekeeping Ecosystem}

This part of the research results presents the orchestrator's business model of the beekeeping ecosystem. The elements of the business model are established after mapping the activities of the orchestrator as it is connected to other ecosystem actors onto the business model canvas as illustrated by Osterwalder and Pigneur (2010).

\section{Customer Segments}

The beekeeping industry in Tanzania serve different customer segments like local brewers, traditional healers, and individuals in both rural and urban markets. But the most important customer segment for the honey product is urban customers who have relatively higher incomes than rural households. The beekeeping ecosystem has to target urban markets which represent a relatively profitable market segment. The orchestrator should focus to serve the individual household customer segment in the urban market.

\section{Value Proposition}

In Tanzania honey is mostly used as a food supplement and medicinal value. Therefore, delivering honey that can perform the healing and nutritional functions is what is important to customers. Customers have the feeling that the nutritional and healing benefits of honey are related to flora and nectar sources. So, they want to trace the sources and origin [the traceability] of the honey they consume. Most urban customers prefer honey from the Western part of Tanzania, in particular, the Tabora and Kigoma regions. They consider it to be pure, natural and organic, and therefore of high quality. The beekeeping ecosystem should define the honey sources, vegetation and nectar source.

Branding is another important value proposition to be delivered. In the Morogoro market, about 26 honey brands are available, competing in different retail stores and supermarkets. Most of these brands are owned by honey traders and some beekeeping community-based organizations (CBOs). The industry architecture should be structured to include these competing brands so that one strong brand can be created in the ecosystem. In this regard, the value proposition offered by the orchestrator in the beekeeping ecosystem is the promise to deliver quality and unadulterated honey brand from an accustomed source.

\section{Channels}

Most honey customers prefer direct channels because they think that when indirect channels are used, first, honey can stay longer on the shelves before reaching them. Secondly, untrusted middlemen can mix the honey with edible oils, sugar syrup, and morasses - honey can be adulterated. Also, other customers prefer convenience channels and therefore indirect channels can be used. Therefore, the orchestrator can reach customers through a mix of both direct and indirect channels. 
Customers' word of mouth seems to be a strong communication tool in the Tanzanian beekeeping industry. Also, the use of social media like Instagram, Whatsapp, Facebook, and Twitter show promising growth as well as more effective for communication and customer service. In this regard, a mix of strategies and techniques should be used to promote honey products. This includes word of mouth, social media, trade fairs, exhibitions, and a blog.

\section{Customer Relationships}

In the beekeeping industry in Tanzania, communal relationships or social interaction dominates the customer relationship. Most customers want to buy honey from the source they know, referred to by friends, and if possible socially interact: social ties are more important than commercial ones. Furthermore, the creation of informal ties with customers like asking for feedback through social networks was found to be another way of managing the customer relationship. For example, a customer can share some graphics of a bottle of honey to show and express the feeling with the piece. Also, through social media, an ecosystem actor can share, demonstrate, explain, and clarify things to other actors, including customers. This builds trust, confidence, and hence strengthens the relationships. Therefore, the orchestrator should build both personal assistance and self-service relationships with customers. This type of relationship complements the direct and indirect channels that are used to reach customers. Also, the orchestrator should build community customer relationships through social media and community groups as is the new and effective way of reaching customers in emerging markets.

\section{Revenue Streams}

In the beekeeping industry in Tanzania, customers are willing to pay for the quality, branded honey coming from well-known sources. If customers are certain about the source or origin of the honey product, they are more confident and willing to buy than when they are not informed. In this case, honey traceability and the absence of contaminants are important. Also, customers are willing to pay more for branded honey: the price of honey hinge on brand image. For example, in one supermarket we observed that some imported brands were selling more than local brands despite their higher prices. When we asked the outlet owner for an explanation, we found that the customers' perception of quality due to branding increased customers' willingness to pay more for the product.

Furthermore, when beekeepers work together in an ecosystem approach, they can capture value from the orchestrator through both fixed and negotiated pricing models. However, to encourage beekeepers to stay in the ecosystem, and discourage their side selling behavior, a negotiated price model is encouraged. The orchestrator should negotiate at either the same or slightly above market price. This will increase the ability of beekeepers to capture relatively higher value hence build trust, and strengthen business relationships and cooperation among ecosystem members.

Regarding the payment preferences, most beekeepers prefer cash on delivery payment models; they want to be paid as soon as they deposit or deliver honey. In some cases, pre-payment can be made especially when the actors have trust and good social and business relations such that beekeepers cannot opt for side selling. In the case of selling to customers in the urban market, the payment model is different: both cash and credit sales are practiced. Customers can buy honey on credit and pay at the end of the month, ideally, when customers get salaries. In most cases, payments are done through mobile finances commonly known as "M-Pesa".

In this regard, the revenue stream of the orchestrator in the beekeeping ecosystem depends on the transaction revenues. The revenue comes from selling packed honey; different packs for diverse consumers through both cash and credit sales. Also, both negotiated and fixed pricing models should be used depending on the grade of the honey product, volume or quantity, and the type/characteristic of a customer segment. 


\section{Key Resources}

In the beekeeping ecosystem the orchestrator has to organize different types of resources. Key physical resources include hives, bee suits, harvesting materials, processing room/house, processing, and packaging machines, and packaging material. In the case of human resources, beekeeping is a knowledgeintensive industry. Therefore, upgrading beekeeping knowledge and skills is crucial to professionalize the industry and, consequently, produce more and better honey and increase value creation in that way. Moreover, individual actors in the industry are limited by financial resources to invest; beekeepers are the most constrained actor. Therefore, the orchestrator should organize other actors so that they could cooperatively invest in the beekeeping ecosystem.

\section{Key Activities}

In the beekeeping industry, key activities include honey production (apiary management, bee colony management, harvesting, and storage), aggregation, processing (extraction, refining or filtration, blending, creaming, and de-crystallization), packaging, and trading.

\section{Key Partnerships}

In the beekeeping industry in Tanzania, key partners in the beekeeping ecosystem include suppliers, producers, traders, transporters, and customers. The orchestrator should, therefore, organize these key partners to a beekeeping ecosystem. We also found that most beekeepers are ready to work in partnerships; partnering among themselves, and with other actors in the beekeeping ecosystem. For example, some beekeepers have been working in small community groups containing up to 30 members or beekeepers. However, when it comes to the form and type of partnership, no beekeeper was ready to form cooperation; they explicitly said that they are not interested at all in forming a cooperative. In this case, the orchestrator can think of any other form of partnership, but not a cooperative.

\section{Cost Structure}

The most important costs inherent in the beekeeping ecosystem is the production and processing costs. The beekeeping equipment and tools like beehives, suits, and harvesting materials; honey processing facilities like the collection house, processing, and packaging machines are the most expensive resources. Moreover, apiary management, management of the collection center and operating the processing center, honey processing, and packaging, trading, and transportation are the most expensive activities. In this regard, the orchestrator should organize funds to finance both the production and processing costs in the beekeeping industry.

\section{Discussion of the Findings}

In this study, we consider how the beekeeping industry architecture can be changed through a business ecosystem approach. We examine how different firms in the beekeeping industry can be orchestrated to present a value proposition to target customers; creating value and sharing of revenue among ecosystem members. The business ecosystem comprises sets of actors with different assets and capabilities who play different roles and are involved in different activities to present the value proposition. From such a perspective, who is involved and why they are involved becomes important in presenting value proposition and value capture through the recombination of beekeeping resources. Therefore, we used the business model canvas and value chain to examine the elements of the orchestrator's business model in the beekeeping ecosystem and described the activities performed by every single actor in the ecosystem to create value and share revenue. Specifically, we emphasize how to change the beekeeping IA by focusing on the interactions between and interdependence of those actors, and the resources at the time of their involvement in recombination rather than on whether those actors fall on the production or consumption side.

The beekeeping ecosystem should have the following categories of core actors in its value-creating system: suppliers, the producer group (beekeepers), the orchestrator, honey traders, and customers. These actors should be coordinated and interlinked not only to the orchestrator but also among themselves so 
that they can deliver quality honey to the target customer. For example, local carpenters can be connected to beekeepers such that they supply - make and repair - quality hives. Also, the orchestrator should be connected to traders to effectively utilize the traders' market channel. In this regard, the IA should be structured as shown in figure 1 below such that ecosystem actors can integrate resources towards value proposition.

\section{FIGURE 1 \\ THE BEEKEEPING VALUE CHAIN BASED ON THE ECOSYSTEM APPROACH}

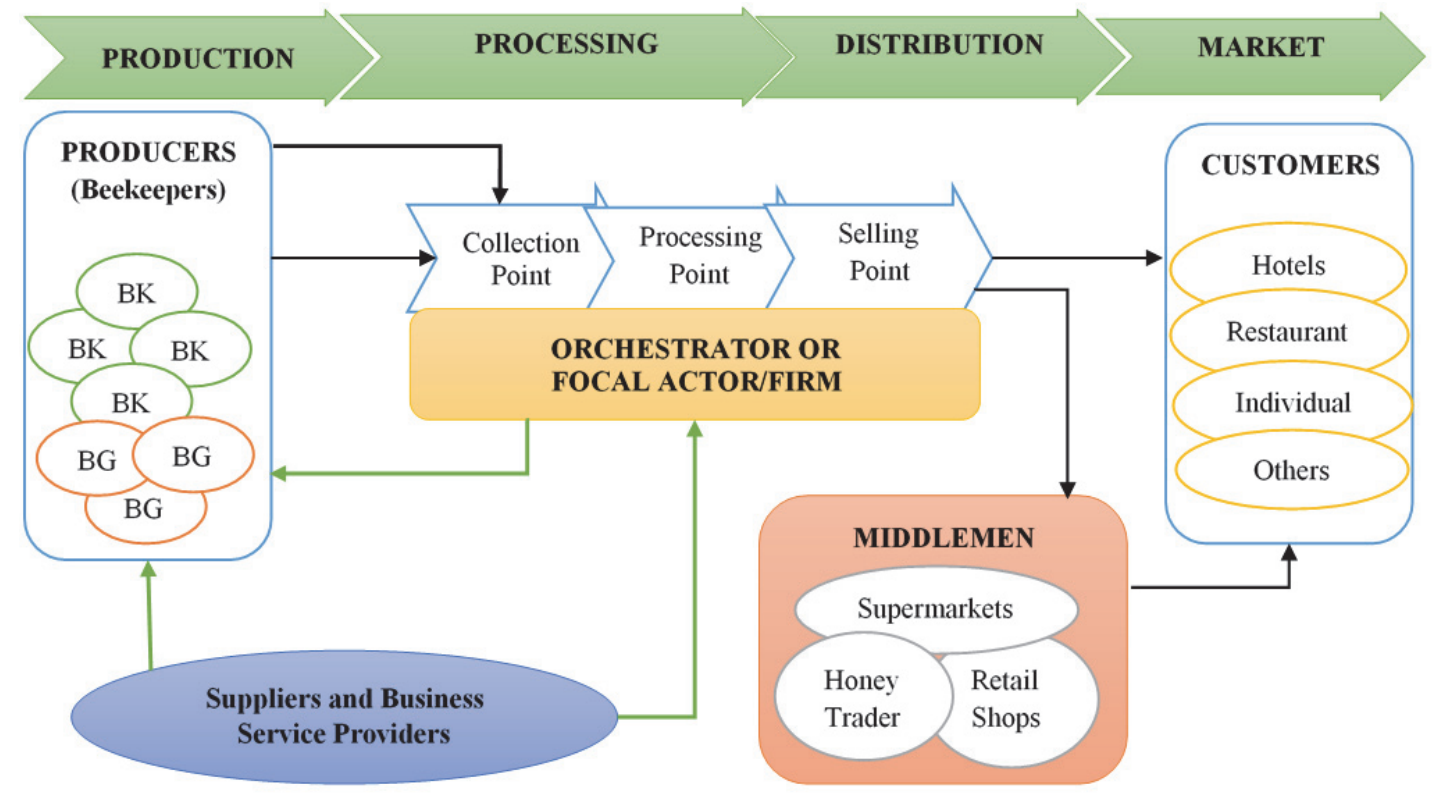

In the first part of the ecosystem in figure 1 above, beekeepers should be connected among themselves, suppliers and business service providers (BSPs), and orchestrator. Interconnection among beekeepers enables them to share experience, knowledge, skills, and resources available (resources integration) within their localities. Also, beekeepers gain higher bargaining power as they have one voice and a relatively larger volume of honey. The connection with suppliers and BSPs enables beekeepers to access business support services, supplies, and finances through "soft" loans. And the connection with the orchestrator enables beekeepers to get access to finances, technical support, and a sustainable market of their produces as they deposit honey to the orchestrator. The orchestrator has to organize finance for some activities, production materials, and facilitate transportation of honey to the collection point. However, this depends much on the agreed governance structure, partnership model, and business relations i.e. the architecture operating/business contracts. Therefore, beekeepers create value through improved efficiency, quality, and productivity. Also, beekeepers can access assets and services which they lack, and could not access outside an ecosystem. The next part of the ecosystem in figure 1 above is the interconnection between the orchestrator, middlemen, and customers - channel management. In this part, the orchestrator should be connected to channel members like supermarkets, and traders so that they can collaboratively reach the target customers. This changes the channel model from competition to collaboration; one [or few] brands are traded in the market, the channel length and the cost of reaching customers are reduced. Also, the orchestrator should "strategically" create some honey-selling point in the target markets. This enables customers to access the product directly from the focal firm, which adds more value to some customers. Therefore, customers in target markets can effectively and efficiently be reached through both direct and indirect channels. Most importantly, customers are efficiently served, and 
brand confusion or dazzle is reduced: Customers are more certain about the honey brands. So, brand trust, brand loyalty, as well as sales volume increase: The ecosystem captures more value.

After organizing the ecosystem actors in the value creation architecture, the next issue is the distribution of roles and activities. It is important to understand what is expected from the ecosystem actor to realize the value proposition. As depicted in figure 1 above, the ecosystem actors should perform the following activities: inputs supply, honey production, honey aggregation or bulking, processing, and trading. The storage and transportation activities are also important and should be integrated throughout the product movement in the value chain.

The beekeeping ecosystem begins with the input supplies where actors have to supply quality and standard inputs. Suppliers in this part include local artisans, professional artisans, private sector organizations that can import and sell beekeeping equipment, and agencies that support the sector. For example, honey refining, and honey creaming machines are among the most important machines for honey processing. But these machines are neither made locally nor available to local beekeepers. Therefore, the orchestrator has to buy, import, or depend on local suppliers to import. In the beekeeping ecosystem, these supplies should be linked with both the beekeepers and the orchestrator so that tools and equipment can reach the target actors accordingly. The role of the orchestrator here is to facilitate the possible interactions and transactions between the trading parties. For example, the orchestrator can pay for beehives which are lent to beekeepers under an agreement that beekeeper will either pay the orchestrator or the supplier. Also, to acquire quality processing and packaging materials from the suppliers, the orchestrator can enter into shared benefits business agreements with suppliers. For example, in a 'business contract' to supply packaging materials, the supplier is assured of the market and the orchestrator is assured of supplies at a 'negotiated' price.

After acquiring supplies, the next activity in the ecosystem is honey production. This is the core activity of the producer group, beekeepers, in an ecosystem. Beekeepers should perform all the activities necessary for the production of quality honey. Focusing on honey production, other ecosystem actors like suppliers and orchestrators should support beekeepers (through improved technology, knowledge and skills) to improve productivity and honey quality. After harvesting, beekeepers deposit their honey to the decided collection points/center. Since most beekeepers are doing the activity as a source of secondary income, and they have not invested enough to produce a sizable volume of honey, it would be very expensive to transfer honey in small batches to the processing point. So, the importance of the collection point here is to bulk honey before they are sent to the processing point/center. In this regard, the most important aspect here is the improved productivity and bulking of honey. Beekeepers should be linked to each other and to the collection point such that they are part of the facility and its operation. The orchestrator should link other industry actors to effectively run the collection point.

After harvesting and collecting honey in the collection point, honey processing is the next activity in the beekeeping value creation system. Honey is a food product, and most customers want to consume safe, clean and healthy products. Therefore, having a hygienic processing facility adds more value to beekeeping products. Therefore, value is created through hygienic processing - refining, aggregation, blending, and packaging. This process is important because it produces a standardized honey product clear honey with similar features like color, and taste. In this regard, the orchestrator should have a decent and well-established honey processing facility; a processing room or house, tools and equipment. Moreover, the firm should invest in human resources to help in ensuring the productivity and quality of honey products, which is important in creating and capturing value in the beekeeping industry. The most important issue in this activity is honey refining, blending, and packaging. Also, the activity should focus to reduce post-harvest losses, increase productivity, product quality, and ensure hygiene.

Channel management is the last activity that the ecosystem actors should focus to efficiently reach the target market. Value is created by efficient management of the trading channel: making honey products available to customers in urban markets. In Tanzania, the urban market is the most potential and profitable market segment as it has customers with relatively higher income. Therefore, reaching this market should be the main focus of the beekeeping ecosystem. The role of the orchestrator, in this case, 
should be to properly coordinate both direct and indirect channels; interact with different channel members like honey traders, retail shops, and supermarkets to efficiently reach target markets.

For the beekeeping ecosystem to efficiently perform these activities a sizeable investment that can well feed into an industry is necessary: but neither beekeepers, orchestrators, nor traders can do this alone. For example, in the existing industry architecture, beekeepers are not able to capture enough value because they are limited to financial resources to invest in the activities and resources. Also, they lack adequate skills and knowledge of commercial beekeeping (Tutuba and Vanhaverbeke, 2018). Therefore, in a situation like this, the multipartite (joint) financing model is necessary; the ecosystem financing which involves multiple actors to enhance access to finance for inputs and market (Vanhaverbeke, 2017). The ecosystem can have different financing models depending on the activities that need to be financed, and the relationship between actors involved. For example, the orchestrator can establish a financing model to beekeepers so that beekeepers can access [finance] production inputs. Modalities like "kopa mzinga lipa asali" meaning "borrow a hive, pay honey" could be initiated and sustained by involving potential stakeholders. Alternatively, producer groups can join into a SACCOS and finance their inputs through it. Also, the orchestrator can link the beekeepers with some beekeeping supporting organizations like NGOs, and government agencies. These organizations can support the actors through capacity building, technology, and market [channels] linkages. In this regard, the industry architecture should be changed such that joining firms cooperatively finance [investment] the activities. The investment model should, however, aim to create lock-in shared relationships among beekeepers, and between actors in the beekeeping ecosystem. All actors should also have a feeling of benefiting from the relationship such that, working out of the ecosystem will have some disadvantages; there is complementarity in both value creation and value capture.

In this regard, to change the beekeeping industry architecture through the business ecosystem approach requires strategies, as summarized in figure 2 below, which should be centered on market linkages framework. The ecosystem framework should work with beekeepers through the collection center. 


\section{FIGURE 2 \\ STRATEGIES TO CHANGE THE INDUSTRY ARCHITECTURE THROUGH THE ECOSYSTEM APPROACH}

\begin{tabular}{|c|c|c|c|}
\hline Chain Activities & Ecosystem advancement issues & Focal firm/actor intervention & Ecosystem Actors \\
\hline $\begin{array}{l}\text { Consumption } \\
\text { Customers }\end{array}$ & $\begin{array}{l}\text { Branding and Promotions. } \\
\text { Information sharing among } \\
\text { ecosystem actors }\end{array}$ & $\begin{array}{l}\text { Explore market framework, } \\
\text { manage customers. } \\
\text { Disseminate information to } \\
\text { ecosystem actors. }\end{array}$ & $\begin{array}{l}\text { BSP, } \\
\text { Retailers, Gvt } \\
\text { agencies, }\end{array}$ \\
\hline $\begin{array}{l}\text { Honey Trading: } \\
\text { Wholesaling. } \\
\text { Retailing. } \\
\text { Transportation. }\end{array}$ & $\begin{array}{l}\text { Manage the ecosystem channel. } \\
\text { Set up supply chain logistics to } \\
\text { both collection centre and market. } \\
\text { Acquire license and permits from } \\
\text { respective authorities. }\end{array}$ & $\begin{array}{l}\text { Set-up distribution modality. } \\
\text { Support traders with channel } \\
\text { management and business } \\
\text { plan issues. } \\
\text { Manage the trading and } \\
\text { licensing issues like TFDA, } \\
\text { TBS, License, barcode, etc. }\end{array}$ & $\begin{array}{l}\text { BSP, PSOs } \\
\text { (transporters } \\
\text { Retailers, W/S), } \\
\text { Government } \\
\text { agencies }\end{array}$ \\
\hline $\begin{array}{l}\text { Processing II } \\
\text { (Refined honey) } \\
\text { Honey refining. } \\
\text { Honey blending. } \\
\text { Aggregation. } \\
\text { Packaging. }\end{array}$ & $\begin{array}{l}\text { Establishing collection centres. } \\
\text { Provide harvesting and storage } \\
\text { equipment to producer groups. } \\
\text { Set-up information data base of } \\
\text { honey depositors (beekeepers). } \\
\text { Set-up state of art high care } \\
\text { processing facility. } \\
\text { Pay depositors as soon as they } \\
\text { deposit honey. }\end{array}$ & $\begin{array}{l}\text { Design and set up collection } \\
\text { and processing centres. } \\
\text { Set up supply or market } \\
\text { linkages contract with PGs. } \\
\text { Ensure quality processing, } \\
\text { packaging and storage of } \\
\text { refined honey. }\end{array}$ & $\begin{array}{l}\text { Government, } \\
\text { PSOs, BSP, } \\
\text { NGOs. }\end{array}$ \\
\hline $\begin{array}{c}\begin{array}{c}\text { Processing I } \\
\text { (semi-refined } \\
\text { honey) }\end{array} \\
\text { Production \& } \\
\text { Aggregation } \\
\text { (comb honey) }\end{array}$ & $\begin{array}{l}\text { Mobilizing, strengthening and } \\
\text { capacitating producer groups - } \\
\text { beekeepers and their CBOs. } \\
\text { Collective harvesting and bulking } \\
\text { of comb (semi-refined) honey in } \\
\text { their production groups. } \\
\text { Transfer honey to collection point. }\end{array}$ & $\begin{array}{l}\text { Design program for PGs } \\
\text { strengthening. } \\
\text { Mobilize and train producers. } \\
\text { Link producers to FIs, and } \\
\text { mobilize to form SACCOs } \\
\text { Link producers to suppliers }\end{array}$ & $\begin{array}{l}\text { Producers, } \\
\text { Government, } \\
\text { BSP, NGOs, } \\
\text { PSOs, POs, } \\
\text { and FIs. }\end{array}$ \\
\hline Inputs Supply & $\begin{array}{l}\text { Tripartite financing model for } \\
\text { commercial honey production } \\
\text { inputs - beehives, bee-suit, } \\
\text { harvesting equipments etc. }\end{array}$ & $\begin{array}{l}\text { Explore tripartite financing } \\
\text { models for beekeepers. } \\
\text { Supply inputs to producer } \\
\text { groups - beekeepers. }\end{array}$ & $\begin{array}{l}\text { PSOs, BSP, } \\
\text { NGOs, POs, } \\
\text { and } \\
\text { Government. }\end{array}$ \\
\hline
\end{tabular}

To make the model operational implies that the orchestrator should identify potential areas of investment, and attract other beekeeping actors to work together. Thereafter, the orchestrator provides embedded services and linkages with beekeeping supporting organizations. But the ecosystem efficiency depends on a consistent and reliable supply of quality honey, flexibility towards payment conditions (smooth and as immediate payments as possible), and effective operation of the collection point. This requires strong commitment, collaboration, and teamwork among ecosystem actors, and long term planning. The orchestrator should observe these opportunities without damaging the trust and business relationship they have with the ecosystem actors, beekeepers in particular. Regarding the business model, the beekeeping industry architecture should be structured to include other ecosystem actors to deliver the value proposition to target customers. All industry actors in the beekeeping ecosystem should be linked to the orchestrator's business model so that they work toward the same value proposition. It takes into consideration that other ecosystem actors work towards delivering the value proposition.

An important observation in the beekeeping industry ecosystem relates to the management of partnerships and costs. Managing relationships across the value chain, and in the business model (key partnerships) create a sharing of complementary assets and hence resolve some industry value creation limitations. For example, beekeepers should not struggle to get finances to buy harvesting equipment while they can get them from the orchestrator or ecosystem suppliers. Similarly, changing the business model from a fixed cost to variable cost model benefits partners to reduce operating costs and hence 
create more value. For example, harvesting and working in the processing room is not full-time activities. Therefore, human resources can be equipped with different skills such that they work on short-term contracts in the value chain activities. For example, a person can work with beekeepers during the harvest time, and then work in the processing room during honey processing. In this case, all firms in the beekeeping value chain will co-create value focusing on customers' needs. As a result, they grow the size of the pie, through which everyone can increase their value appropriation.

\section{Conclusion and Implications}

Changing the beekeeping industry architecture from a transactional to an ecosystem-based value chain does not happen spontaneously. It requires a determined mind change, commitment, and long term planning. Also, shaping the business model by an orchestrator and aligning other potential organizations with different assets and competencies into a business ecosystem. Not only the competencies of the participating firms but also how the ecosystem is structured and managed determines the collective competitiveness of the latter. The ecosystem orchestrates beekeeping actors via a collection point where commercial volume can be achieved through aggregation. This architecture improves beekeepers' ability to capture more value as they can access potential and profitable markets as well as complementary assets to efficiently produce honey, i.e. to improve productivity. Furthermore, collaborative channel management lower competition as traders sell the same brand and serve the same customer segment: The orchestrator brand the honey during the processing stage, and pass it to ecosystem traders in the distribution channel. In this regard, changing the industry architecture through an ecosystem [collaborative] approach increases the size of the pie as well as the pie of industry actors in the ecosystem. Beekeepers improve their value creation and value capture abilities by the new business opportunities that could not have been seized without the business ecosystem.

Therefore, value creation and value appropriation are influenced by business models and collective forms of action by firms participating in the industry. This involves collective decision-making among beekeeping value chain actors to work together to create proper value propositions that meet the expectations of specific consumer segments. An efficient ecosystem creates value by including ecosystem actors in the value creation process and produce the right value proposition for the right customer segment. The product should reach customers in time through appropriate channels, and key activities and resources should be managed and integrated among value chain members. This reduces waste and improves the cost structure. This, in turn, allows firms to capture more value and benefit all chain members. When the benefits are shared across the chain, suppliers, beekeeper, processors, honey traders, and customers become partners rather than rivals.

\section{REFERENCES}

Adner, R. (2017). Ecosystem as Structure: An Actionable Construct for Strategy. Journal of Management, 43(1), 39-58. DOI: 10.1177/0149206316678451

Adner, R., \& Kapoor, R. (2010). Value creation in innovation ecosystems: How the structure of technological interdependence affects firm performance in new technology generation. Strategic Management Journal, 31(3), 306-33.

Adner, R., \& Kapoor, R. (2016). Innovation Ecosystems and the Pace of Substitution: Re-Examining Technology S-Curves. Strategic Management Journal, 37(4), 625-648. http://dx.doi.org/10.1002/smj.2363

Amit, R., \& Zott, C. (2001). Value creation in e-business. Strategic Management Journal, 22, 493-520.

Amit, R., \& Zott, C. (2012). Creating Value Through Business Model Innovation: Could your company benefit from a new business model? Consider these six questions. Strategic Management Review, 53(3), 40-49.

Amit, R., \& Zott, C. (2016). Business Model. Augier, M., and Teece, D. J. (eds.), The Palgrave Encyclopedia of Strategic Management. DOI 10.1057/978-1-349-94848-2_335-1 
Chesbrough, H., Vanhaverbeke, W., \& West, J. (2006). Open Innovation: Researching a New Paradigm. Oxford University Press.

Collins, R. C., Dent, B., \& Bonney, L. B. (2015). A guide to value-chain analysis and development for Overseas Development Assistance projects. Australian Centre for International Agricultural Research: Canberra ACT 2601, Australia.

Elliott, R., \& Timulak, L. (2015), Descriptive and interpretive approaches to qualitative research. $A$ Handbook of Research Methods for Clinical and Health Psychology, 2005, 147-159.

Gawer, A., \& Cusumano, M. A. (2014). Industry platforms and Ecosystem Innovation. Journal of Production Innovation Management, 31(3), 417-433.

Gawer, A., \& Cusumano., M., A. (2008). How companies become platform leaders. MIT Sloan Management Review, 49(2), 28-35.

Guyo, S., \& Solomon, L. (2015). Review on Beekeeping Activities, Opportunities, Challenges and Marketing in Ethiopia, Journal of Harmonized Research in Applied Sciences, 3(4), 201-214.

Hyrynsalmi, S., Seppänen, M., \& Suominen, A. (2014). Sources of value in application ecosystems. The Journal of Systems and Software, 96, 61-72.

Iansiti, M., \& Levien, R. (2004). The keystone advantage: What the new dynamics of business ecosystems mean for strategy, innovation, and sustainability. Boston, MA: Harvard Business School Press.

International Trade Centre. (2015). Tanzania Honey Sector Synthesis Report and Development Road Map. Geneva, Switzerland.

Jacobides, M. G. (2016). Augier, M. Teece, D.J. (eds.), The Palgrave Encyclopaedia of Strategic Management. DOI 10.1057/978-1-349-94848-2_390-1

Jacobides, M. G., \& Kudina, A. (2013). How industry architectures shape firm success when expanding in emerging economies, Global Strategy Journal, 3, 150-170. DOI: 10.1111/j.20425805.2013.01054.x

Jacobides, M. G., Cennamo, C., \& Gawer, A. (2018). Towards a theory of ecosystems. Strategic Management Journal, 1-22

Jacobides, M. G., Knudsen, T., \& Augier, M. (2006). Benefiting from innovation: Value creation, value appropriation and the role of industry architectures. Research Policy, 35(6), 1200-21.

Kapoor, R. (2018). Ecosystems: broadening the locus of value creation. Journal of Organization Design, 7(12), 1-18

Leten, B., Vanhaverbeke, W., Roijakkers, N., Clerix, A., \& Van Helleputte, J., (2013). IP models to orchestrate innovation ecosystems: IMEC, a public research institute in nano-electronics. California Management Review, 55(4), 51-64.

Moore, F. J. (2006). Business ecosystem and the view from the firm. Antitrust Bulletin; Spring 2006, 51(1), 31-75.

Moore, J. F. (1993). Predators and Prey: The New Ecology of Competition. Harvard Business Review, 71(3), 75-83.

Mwakatobe, A., \& Mlingwa, C. (2006). Tanzania - The status of Tanzanian honey Trade, Domestic and International Markets. Tanzania Wildlife Research Institute, Arusha.

Osterwalder, A., \& Pigneur, Y. (2010). Business Model Generation: A Handbook for Visionaries, Game Changers, and Challengers. John Wiley \& Sons, Hoboken, New Jersey, USA

Pisano, G., P., \& Teece, D., J. (2007). How to capture value from innovation: Shaping intellectual property and industry architecture. California Management Review, 50(1), 278-296.

Porter, M. (1996). What is a strategy? Harvard Business Review, Nov-Dec, pp. 61-78.

Saunders, M., Lewis, P., \& Thornhill, A. (2009), Research Methods for Business Students, 5th edition. Harlow: Pearson Education.

Tee, R., \& Gawer, A. (2009). Industry architecture as a determinant of successful platform strategies: a case study of the i-mode mobile Internet service. European Management Review, 6, 217-232.

Teece, D. J. (2016). Business ecosystem. Augier, M. and Teece D. J. (eds.), The Palgrave Encyclopedia of Strategic Management. DOI 10.1057/978-1-349-94848-2_724-1 
Teece, D., J. (2018a). Profiting from innovation in the digital economy: Enabling technologies, standards, and licensing models in the wireless world. Research Policy, 47 1367-1387.

Teece, D., J. (2018b). Business models and dynamic capabilities. Long Range Planning. 51 (2018) 40-49.

Tsujimoto, M., Kajikawa, Y., Tomita, J., \& Matsumoto, Y. (2018). A review of the ecosystem concept Towards coherent ecosystem design. Technological Forecasting \& Social Change, 136: 49-58.

Tutuba, B. N., \& Vanhaverbeke, W. (2018), Beekeeping in Tanzania: why is beekeeping not commercially viable in Mvomero? Afrika Focus, 31(1), 213-239.

Tutuba, B. N., \& Msamula, S. J. (2018), Ufugaji nyuki kibiashara: Nadharia na vitendo. Mzumbe University, Villex publishing co, Dar es salaam.

Tutuba, N. B., Msamula, J. S., \& Tundui, H. P. (2019). Business Model Innovation for Sustainable Beekeeping in Tanzania: A Content Analysis Approach. American Journal of Management, 19(1) 74-88.

Vanhaverbeke, W. (2017). Managing Open Innovation in SMEs. University Printing House, United Kingdom.

Vanhaverbeke, W., \& Cloodt, M. (2006). Open innovation in value networks. Chesbrough, H., Vanhaverbeke, W., and West, J. (eds.) Open Innovation: Researching a New Paradigm. Oxford University Press, 258-281.

Yaghmaie, P., \& Vanhaverbeke, W. (2019). Identifying and describing constituents of innovation ecosystems: A systematic review of the literature. EuroMed Journal of Business, 1450-2194. DOI 10.1108/EMJB-03-2019-0042

Yin, R.K. (2014), Case study research: Design and methods, 5th Edition. Sage Publications, Los Angeles, United States.

Zott, C., \& Amit, R. (2013). The business model: A theoretically anchored robust construct for strategic analysis. Strategic Organization, 11(4), 403-411. DOI: 10.1177/1476127013510466

Zott, C., Amit, R., \& Massa, L. (2011, July). The Business Model: Recent Developments and Future Research. Journal of Management, 37(4), 1019-1042. DOI: 10.1177/0149206311406265 